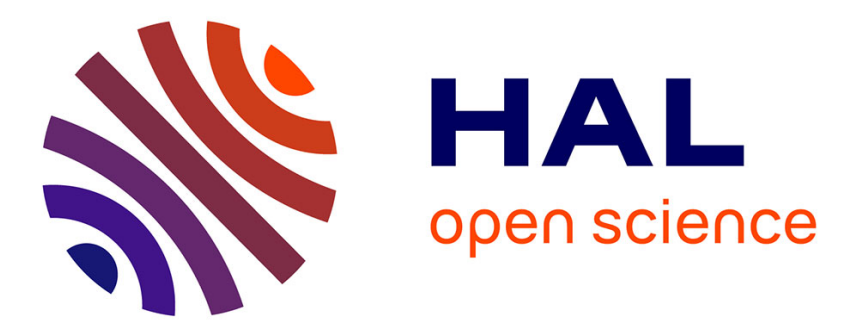

\title{
Numerical investigation of the radial cold rolling process of the grooves
}

Eduard Laurentiu Nitu, Daniela Monica Iordache, Claudiu Badulescu

\section{To cite this version:}

Eduard Laurentiu Nitu, Daniela Monica Iordache, Claudiu Badulescu. Numerical investigation of the radial cold rolling process of the grooves. Proceedings of the Institution of Mechanical Engineers, Part B: Journal of Engineering Manufacture, 2021, 236 (3), pp.095440542110245. 10.1177/09544054211024571 . hal-03271427

HAL Id: hal-03271427

https://hal-ensta-bretagne.archives-ouvertes.fr/hal-03271427

Submitted on 29 Jun 2021

HAL is a multi-disciplinary open access archive for the deposit and dissemination of scientific research documents, whether they are published or not. The documents may come from teaching and research institutions in France or abroad, or from public or private research centers.
L'archive ouverte pluridisciplinaire HAL, est destinée au dépôt et à la diffusion de documents scientifiques de niveau recherche, publiés ou non, émanant des établissements d'enseignement et de recherche français ou étrangers, des laboratoires publics ou privés. 


\section{Numerical investigation of the radial cold rolling process of the grooves}

\author{
Eduard Laurentiu Nitu' ${ }^{(D}$, Daniela Monica lordache' and Claudiu \\ Badulescu ${ }^{2}$
}

Proc IMechE Part B:

$J$ Engineering Manufacture $1-12$

(C) IMechE 202।

Article reuse guidelines:

sagepub.com/journals-permissions DOI: 10.1177/0954405421102457| journals.sagepub.com/home/pib (S)AGE

\author{
Badulescu
}

\begin{abstract}
The radial cold rolling process is widely used in industry due to the advantages of chip removing processing. In this study, circular complex profiles were formed by cold-rolling with radial feed, using a patented device with two roller-tools. By achieving several numerical simulations of the radial rolling process, the study aimed to establish the influence that the maximum set force and the diameter of the workpiece have on the productivity of the process and the quality of the formed trapezoidal and metric grooves. The numerical simulations were performed with ABAQUS/Explicit software and by using a previously validated finite element model. The penetration curve of the roller-tools in the material was introduced in the simulation as an analytical function and was determined based on experimental researches. To express the dependency of the penetration curve coefficients on other rolling conditions, a multivariable analysis using a design of experiments technique was performed. The parameters that result from numerical simulations and were analyzed in this study are the profile forming time, the maximum radial force, the distribution of the equivalent strains in the axial section of the profiles, and the profile dimensions. The conclusions that were drawn from the analysis of the results regarding the influence of the set maximum force and the workpiece diameter on the analyzed parameters of the numerical simulations, together with the definition of efficient process criteria, allowed also the identification of the optimal conditions of the rolling process.
\end{abstract}

\title{
Keywords
}

Radial cold rolling, groove profile, rolling device, finite element modeling, ABAQUS

Date received: 10 August 2020; accepted: 23 May 202I

\section{Introduction}

Cold forming presents major advantages compared to the cutting processes ${ }^{1-6}$ : (i) more productive, (ii) no production of chips, and (iii) high quality of the generated surface. Moreover, because the deformation occurs at ambient temperature, the initial properties of the material are irreversibly changed, forming a continuous fiber in the material of the part, which ensures better mechanical properties, ${ }^{7-9}$ such as: roughness, micro-hardness, and fatigue resistance.

Radial cold rolling with two roller-tools is increasingly used in industry to obtain parts with complex profiles (threads, grooves, etc.) on revolution pieces, generally for series production, ${ }^{2-6}$ and are in continuous development and competition concerning the quality and cost of products. The trend is oriented toward developing and implementing numerical modeling which represents a very useful and efficient tool for successful the experimental researches.

The finite element modeling of the cold rolling process started in the 1990 s by Rowe et al., ${ }^{10}$ but the high volume of calculations and the limited capacity of computers to handle a large amount of data, within a reasonable time, restricted these studies to the understanding of the deformation process. Martin ${ }^{11,12}$ used finite element analysis based on MARC finite element code and, using a 2D plane strain finite element model, has established an adequate mesh to investigate the residual stress for a thread profile obtained by radial cold rolling. This process was also investigated by Domblesky and Feng through several numerical models and methods implemented in the finite element code DEFORM. First, by using a 2D plane strain finite

\footnotetext{
'Manufacturing and Industrial Management Department, University of Pitesti, Pitesti, Romania

${ }^{2}$ ENSTA Bretagne, IRDL-UMR CNRS 6027, F-29200 Brest, France

\section{Corresponding author:}

Eduard Laurentiu Nitu, Manufacturing and Industrial Management Department, University of Pitesti, Târgul din Vale Street No. I, Pitesti I 10040, Romania.

Email: eduard.nitu@upit.ro
} 
element model, Domblesky and Feng ${ }^{13}$ analyzed the effect of workpiece diameter, friction on thread formation, flow stress, and thread form on material flow and thread profile in external thread rolling of large diameter workpieces. Furthermore, they have developed a three-dimensional numerical model for fat-die thread rolling to incorporate the effects of both groove orientation and workpiece movement in the simulation. ${ }^{14}$ Kamouneh et al. ${ }^{15}$ investigated the work hardening effect of flat rolling on the critical regions of gear through the use of hardness maps, grain-flow photographs, and finite element models developed in ABAQUS and DEFORM. Also, using numerical simulations, they have optimized the shape and the size of the workpiece, ${ }^{16}$ to reduce the negative effects such as the "rabbit ear" phenomenon. Song et al. ${ }^{17}$ used numerical simulations to study the influence of process parameters on small threads obtained by rolling. Kowalik and Trzepieciński ${ }^{18}$ estimated the deformation force and the influence of friction on the material flow in the rolling process of the longitudinal channels using numerical simulation and MARC software. Kukiełka et al. ${ }^{19}$ have developed an application of numerical analysis in the ANSYS program to both determine and analyze the effects of friction coefficient, initial yield stress, and plastic hardening modulus that are used in the numerical simulation of the cold rolling of the external round thread. Cui et al. ${ }^{20}$ have investigated the deformation mechanism and have improved the spline shaft performance obtained by axial-infeed incremental rolling by using 3D DEFORM software. Ma et al. ${ }^{21,22}$ have investigated the gear roll-forming process with axial-infeed using Finite Element Method (FEM) simulations (3D DEFORM software), have developed an analytical model for predicting the pitch error of gear, and also have optimized the geometric design of rolling tool to reduce the deflection and root stress of rolling tool's teeth, to both eliminate the scratches on tooth flank of the formed gear and to reduce the height of rabbit ear. Kramer and Groche ${ }^{23}$ have modeled the thread rolling process using Simufact Forming v13 and have made a systematic study of the influence of the process configuration and the specimen preparation toward the occurrence of defects in rolling processes. Results show that the tribological system influences the rolling process. Yuan et al. $^{24}$ have investigated the influence of roller motion on profile and hardness of T2 worm using numerical modeling (software Forge ${ }^{\mathrm{TM}}$ ) and experiments. Zhang et al. ${ }^{25}$ have investigated the deformation mechanism in the self-infeed rolling process of thread shaft using DEFORM 3D software, showing the behavior of material flow and material hardening. They also investigated ${ }^{26}$ the protrusion generation in the forming process of long threads by axial self-infeed rolling process, establishing that to reduce the protrusion height, the pre-rolling angle should be $2^{0}$.

In concluding this survey, it may be stated that numerical analysis is a powerful and reliable tool for manufacturing process investigation. The accumulated knowledge has enabled the forming industry to improve process competitiveness, product performance, and service life.

Through numerical simulation in the ABAQUS environment, this paper examines the influence that the maximum set force and diameter of the workpiece have on both the process productivity and the quality of circular profiles obtained by radial cold rolling with a patented device. The elements that are analyzed in the study are the profile forming time, the maximum radial force, the profile dimensions, and the equivalent strains distribution in the axial section of the profiles. Three criteria are defined to evaluate the process efficiency: (i) process productivity, (ii) material hardening, and (iii) profile dimensions.

\section{Experimental work}

\section{Processed material and profiles}

The material used in this investigation was AISI 1015. Its chemical composition and mechanical characteristics are given in Table 1. The workpieces were obtained by turning and grinding from a hot extruded bar.

The profiles formed by radial cold rolling using two roller-tools and in-feed method were a concentric channels surface as in Figure 1(a), with five similar grooves in axial section for metric thread M20x2, respectively, for trapezoidal thread $\operatorname{Tr} 20 \times 2$. Geometric characteristics of the two types of profiles are shown in Figure 1(b) and (c).

\section{Experimental system}

The radial cold rolling process was performed by applying the kinematic scheme in Figure 2(a) on a lathe using an experimental system represented schematically in Figure 2(b). The patented device, Ungureanu et al., ${ }^{27}$ is shown in Figure 2(c) and is described in detail by Iordache et al. ${ }^{28}$

Table I. Chemical composition and initial mechanical characteristics of the steel AISI I0I5.

\begin{tabular}{|c|c|c|c|c|c|c|c|c|c|c|}
\hline \multicolumn{7}{|c|}{ Chemical composition (wt \%) } & \multicolumn{4}{|c|}{ Mechanical characteristics } \\
\hline $\mathrm{C}$ & $M n$ & $\mathrm{Cr}$ & $\mathrm{Si}$ & $\mathrm{Ni}$ & Mo & $p, S$ & $\mathrm{RP}_{0,2}\left(\mathrm{~N} / \mathrm{mm}^{2}\right)$ & $\mathrm{Rm}\left(\mathrm{N} / \mathrm{mm}^{2}\right)$ & A5 (\%) & $\mathrm{HV}_{0,3}(\mathrm{MPa})$ \\
\hline 0.15 & 0.65 & 0.11 & 0.27 & 0.08 & 0.01 & $<0.035$ & 298 & 475 & 15 & 139 \\
\hline
\end{tabular}




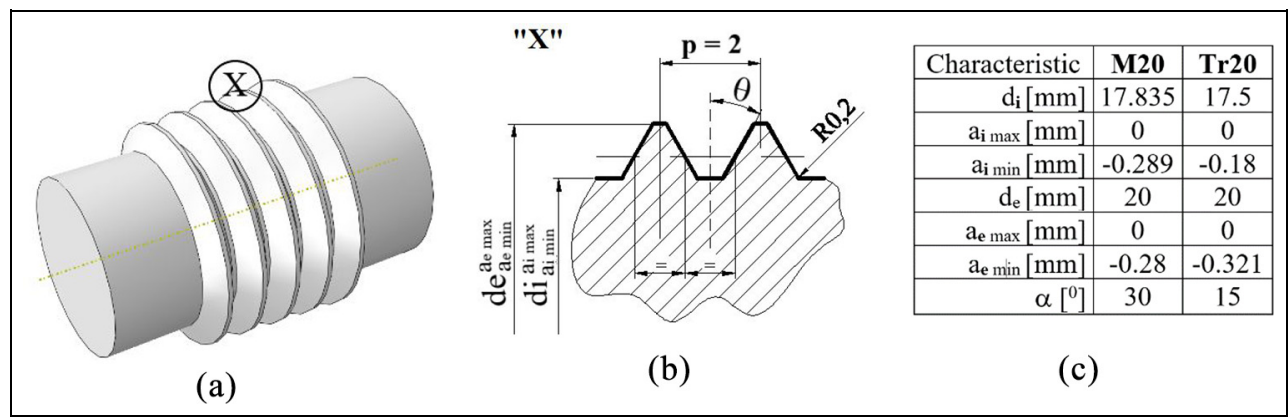

Figure I. Form of the cold rolling profiles: (a) 3D drawing, (b) $X$ detail, and (c) dimensions and deviations of the two types of profiles.

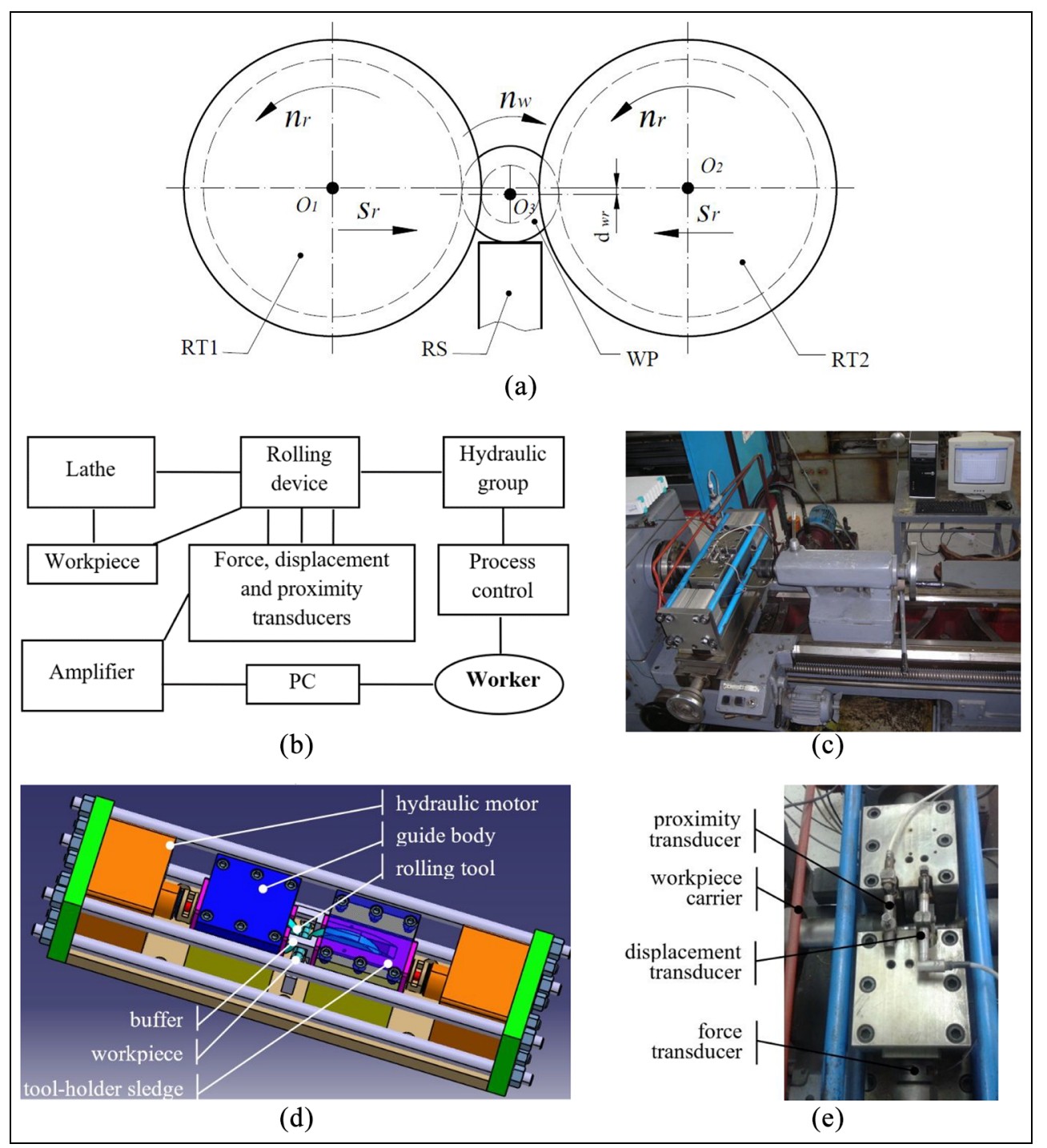

Figure 2. Experimental system for the radial cold-rolling: (a) kinematic scheme, (b) general scheme, (c) general photography, (d) CAD model of the rolling device, and (e) positioning of transducers.

This device is fixed on a lathe carriage and the working cycle (performed by the two roller-tools) is semiautomated: penetration, calibration, withdrawal. The roller-tools (RT) are entrained in rotation by the workpiece at the speed $\left(n_{\mathrm{r}}\right)(\mathrm{rpm})$ as a result of the contact between the rolls and the workpiece. The radial feed of the roller-tools $\left(s_{\mathrm{r}}\right)$, the same for the two rolls, but in the opposite direction, is generated by two hydraulic motors Figure 2(d). The maximum force developed by each hydraulic engine, denoted as maximum set force $\left(F_{\mathrm{m}}\right)$, can be adjusted by setting an equivalent pressure $\left(p_{\mathrm{h}}\right)$ in the two hydraulic engines. 


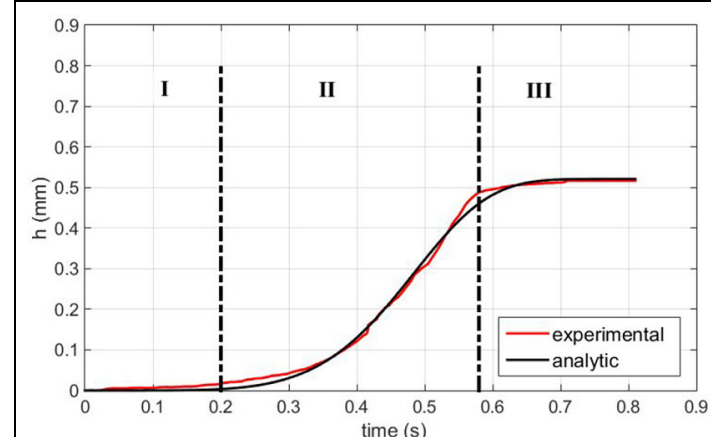

(a)

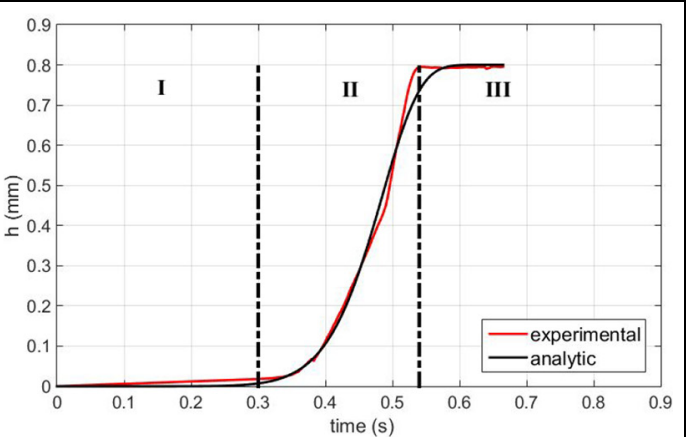

(b)

Figure 3. The penetration curves of the roller-tools for rolling conditions $n=1600 \mathrm{rpm}, p=36$ bar: (a) metric profile and (b) trapezoidal profile.

The rolling speed $(v)$ can be adjusted by the lathe speed setup $\left(n_{\mathrm{w}}\right)$, while the radial feed of the roller-tools $\left(s_{\mathrm{r}}\right)$ cannot be directly adjusted, except through the pressure $p$ in the hydraulic motors. The penetration depth of the roller-tools $(h)$ can be limited using buffers. When this depth is reached $\left(h_{\max }\right)$, the calibration of the profile can be performed by maintaining in rotation the roller-tools in the final position to give the piece a high geometrical and surface quality.

The experimental system allows monitoring the roller-tools displacement, the radial force, and the calibration time. Measurement of the roller-tools displacement is carried out with a displacement transducer WAL20, Figure 2(e), and with a resolution of $1 \mu \mathrm{m}$. The radial force (force evolution in the displacement direction of the roller-tools) $\left(F_{\mathrm{r}}\right)$ is measured using a force transducer KMR 200 WAL20, Figure 2(e), whose measurement error is equal to $1 \%$. The calibration phase is controlled by a proximity transducer PY 152, allowing the adjustment of the roller-tools to be held in time in this position.

\section{Penetration curve of the roller-tools}

In the finite element model, it is necessary for the numerical simulation of the rolling process, to define the penetration curve of the roller-tools in the material. Our rolling process is performed with variable radial feed $\left(s_{\mathrm{r}}\right)$ because the time required to reach the set maximum pressure in the experimental system is comparable to the time required to obtain the profile. The experimental shapes of the penetration curves of the rollertools into the material, Figure 3, are similar to the two processed profiles, three areas are being highlighted:

- first area (I) with progressive acceleration, at the beginning of the process, is associated with the elastic deformation of the system;

- second area (II) with an almost constant evolution speed and associated with the plastic deformations of the workpiece;
- third area (III) with a deceleration to a possible saturation and which appears when the profile of the piece has been made or the tool-holder sledge reached the buffer.

The penetration depth of the roller-tools in the material $(h)$ depends on several factors and the most important are the rolling speed $(v)$, the maximum set force $\left(F_{\mathrm{m}}\right)$, and the maximum penetration depth of the roller-tools $\left(h_{\max }\right)$. The form of the law that best describes the evolution of the roller-tools penetration in the workpiece was established after several attempts as follows ${ }^{29}$ :

$$
h\left(t, v, F_{m}\right)=h_{\max }\left(1-\exp \left(-\beta\left(v, F_{m}\right) \cdot t^{\alpha\left(v, F_{m}\right)}\right)\right)
$$

where: $t$ is the process time and the coefficients $\alpha\left(v, F_{m}\right)$ and $\beta\left(v, F_{m}\right)$ depends on the rolling conditions. The values of the coefficients $\alpha\left(v, F_{m}\right)$ and $\beta\left(v, F_{m}\right)$ were determined by regression analysis using the experimental curves of the penetration of the roller-tools in the workpiece. The values of the coefficient of determination $R^{2}$ were over 0.98 , thereby confirming the accuracy of the proposed model.

To express the dependency of the coefficients $\alpha$ and $\beta$ on other rolling conditions $\left(v, F_{\mathrm{m}}\right)$, we performed a multivariable analysis using a design of experiments technique, ${ }^{30,31}$ aiming to determine the parameters of functions as:

$$
\begin{aligned}
& \alpha\left(v, F_{m}\right)=C_{\alpha} \cdot v^{X_{\alpha}} F_{m}{ }^{Y_{\alpha}} \\
& \beta\left(v, F_{m}\right)=C_{\beta} \cdot v^{X_{\beta}} F_{m}{ }^{Y_{\beta}}
\end{aligned}
$$

For each type of profile, 12 experiments were performed consisting of the variation of the rolling speed (v) and the set maximum force $\left(F_{\mathrm{m}}\right)$. First, the $\alpha$ and $\beta$ coefficients for each experimental case were determined by regression analysis. Thus, based on the values of the coefficients $\alpha$ and $\beta$ previously determined, the six coefficients $C_{\alpha}, X_{\alpha}, Y_{\alpha}, C_{\beta}, X_{\beta}, Y_{\beta}$ were identified (the confidence bound was set to $95 \%$ ), Table 2 .

Thus, the curve of penetration of the roller-tools used in the numerical model can be obtained through 


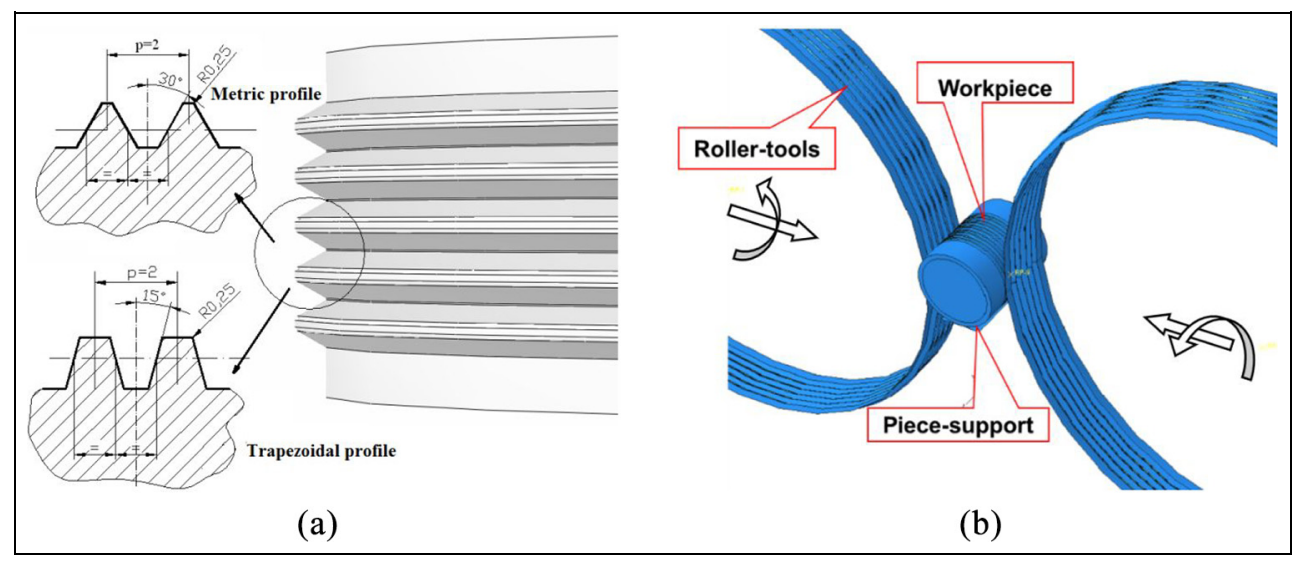

Figure 4. Overview of ABAQUS model for numerical simulation: (a) the roller-tools and (b) kinematic of the process.

Table 2. The functions of the coefficients $\alpha$ and $A$ of penetration curves of the roller-tools.

\begin{tabular}{lll}
\hline Profile & $\alpha$ & $\beta$ \\
\hline M 20 & $\alpha=0.316601 \cdot v^{0.1981} \cdot F_{\mathrm{m}}^{0.6257}$ & $\beta=4.92 \mathrm{E}-08 \cdot v^{0.8455} \cdot F_{\mathrm{m}}^{5.0172}$ \\
$\operatorname{Tr} 20$ & $\alpha=0.738448 \cdot v^{0.3142} \cdot F_{\mathrm{m}}^{0.3334}$ & $\beta=5.99 \mathrm{E}-16 \cdot v^{2.1117} \cdot \mathrm{F}_{\mathrm{m}}^{9.6635}$ \\
\hline
\end{tabular}

equation (1), in which the coefficients $\alpha$ and $\beta$ are obtained by setting the values of the process parameters $v$ and $F_{\mathrm{m}}$ in the functions (2) and (3).

\section{Numerical procedure}

\section{Numerical model}

The numerical simulations were performed with Abaqus/Explicit software. The numerical model used in this study was presented in detail by Nitu et al. ${ }^{32} \mathrm{~A}$ synthetic overview is presented hereafter.

The workpiece used in the simulation has the same (cylindrical) shape and dimensions (diameter and length) as the one used in the experiments. The best compromise between computing resources and results accuracy consists of a different meshing in the axial and radial direction, depending on the profile deformation degree. In the deformed areas C3D8R (8-nodes solid hexahedral elements with reduced integration) are used while in the middle of the workpiece (undeformed area) C3D4R (4-nodes solid tetrahedral elements with reduced integration) are used for the meshing. The different dimensions of the elements in these areas were established based on the profile step $p$.

The roller-tools have a profile associated with the profile to be obtained and are modeled by analytical rigid surfaces (Figure 4). The workpiece is free and in contact with the piece-support, and the roller-tools has two degrees of freedom: a rotation around its axis (given by the rolling speed $v$ ), and an in-feed translation defined by the curve of penetration $h(t)$, equation (1).

The type of contact between the surfaces is a "surface-to-surface" one, the friction coefficient between the rolls and the workpiece was set at 0.3 , and 0.01 between the workpiece and the base. These values were chosen based on the literature review ${ }^{33,34}$ and preliminary simulations.

The behavior of the material is defined as follows:

- the elastic behavior of the workpiece is modeled by assuming isotropic elasticity, with the values of Young's modulus, $E=210 \mathrm{GPa}$ and Poisson's ratio, $\nu=0.3$

- the plastic behavior is described using the von Mises criterion with the assumption of isotropic hardening. Accordingly, the yield function is given by:

$$
f=\sqrt{\frac{3}{2} s_{i j} s_{i j}}-\bar{\sigma}
$$

where $s_{i j}$ are the deviatoric stress components, $\sqrt{(3 / 2) s_{i j} s_{i j}}$ is the von Mises equivalent stress, and $\bar{\sigma}$ is the current yield stress.

The current yield stress $\bar{\sigma}$ can be calculated using the constitutive equation at the deformation of the material. A five-parameter constitutive equation that combines Hollomon and Voce's laws was used:

$$
\bar{\sigma}=\left[K \varepsilon^{n}+S(1-A \exp (-B \varepsilon))\right]
$$

where $K, n, S, A$, and $B$ are material parameters, and $\varepsilon$ is the effective strain.

The identification of the five parameters, equation (5), was performed by fitting the compression test data with a gradient method implemented in a FORTRAN program. ${ }^{32}$ It was obtained: $K=542.5 \mathrm{MPa}, n=0.135$, $S=217.6 \mathrm{MPa}, A=0.99$, and $B=9.91$. 


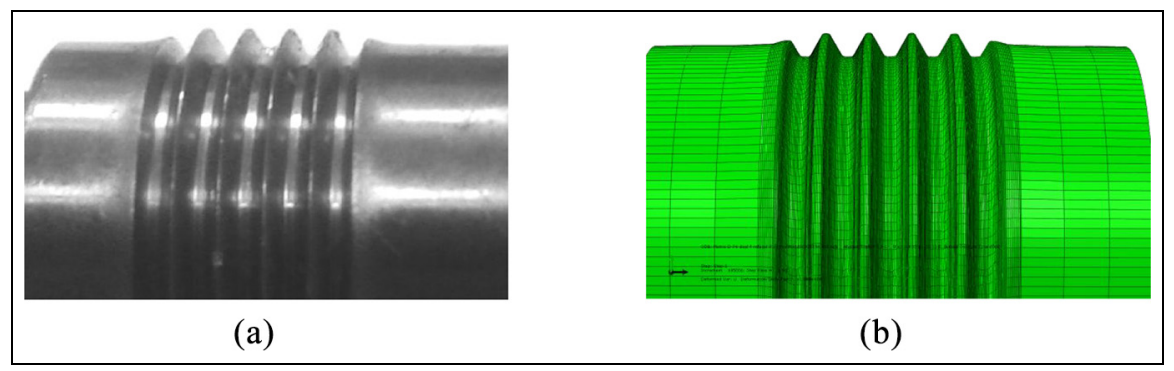

Figure 5. The part obtained by radial cold-rolling: (a) experimental shape and (b) FE simulated shape.

Table 3. The rolling conditions to validate the numerical models.

\begin{tabular}{llll}
\hline Profile & $d_{0}(\mathrm{~mm})$ & $v(\mathrm{~m} / \mathrm{min})$ & $F_{\mathrm{m}}(\mathrm{kN})$ \\
\hline M 20 & 18.80 & 94.50 & 28 \\
Tr 20 & 18.87 & 94.85 & \\
\hline
\end{tabular}

The numerical model validation was performed by comparing the simulation results with the experimental ones, under the rolling conditions presented in Table 3, where $d_{0}$ is the diameter of the workpiece.

The compared output parameters were: profile dimensions $\left(d_{\mathrm{e}}\right.$ and $\left.d_{\mathrm{i}}\right)$, depth of deformation $\left(h_{\mathrm{d}}\right)$, profile height $(H)$, maximum radial force $\left(F_{\mathrm{r} \text { max }}\right)$, and the $\mathrm{HV}_{0,3}$ microhardness level, which is measured in the axial section in the zone of maximum hardening (the transition region of the flanks with the base of the profile).

$$
\begin{aligned}
& \mathrm{h}_{\mathrm{d}}=\left(\mathrm{d}_{0}-\mathrm{d}_{\mathrm{i}}\right) / 2 \\
& \mathrm{H}=\left(\mathrm{d}_{\mathrm{e}}-\mathrm{d}_{\mathrm{i}}\right) / 2
\end{aligned}
$$

A Toolmaster 310-P profile projector, with an accuracy of $\pm 0.5 \mu \mathrm{m}$, was used to measure the geometric parameters of the profile $\left(d_{0}, d_{\mathrm{e}}\right.$, and $\left.d_{\mathrm{i}}\right)$.

Micro-hardness measurements were made by the Vickers method ( $300 \mathrm{~g}$ load) in the axial section of the tooth, using a Zwick Roell ZHV equipment. These values were expressed in $(\mathrm{MPa})$ by multiplying them with the gravitational acceleration value $\left.\left(9.81 \mathrm{~m} / \mathrm{s}^{2}\right)\right)$. The $\mathrm{HV}_{0,3}$ (micro-hardness measurements) and $\bar{\varepsilon}$ (equivalent strains - PEEQ) have been converted based on some assumptions, Tabor, ${ }^{35}$ in the quantities directly comparable, in stress respectively, by expressing them in the same unit (MPa).
A summary of the comparisons between simulated results versus experimental ones is shown in Table 4 and Figure 5. Thus, based on these comparisons it is concluded that all calculated outputs were in very good agreement with their experimental values.

\section{Simulations plan}

The developed numerical model in the ABAQUS environment was used to analyze the influence of the maximum set force $\left(F_{\mathrm{m}}\right)$ and the diameter of the workpiece $\left(d_{0}\right)$ on the productiveness and the quality of circular profiles. The penetration curves of the roller-tools used in this model are defined by the equation (1), the values of the coefficients $\alpha\left(v, F_{m}\right)$ and $\beta\left(v, F_{m}\right)$ being calculated with the formulas presented in Table 2.

For the maximum set force $\left(\mathrm{F}_{\mathrm{m}}\right)$, we selected three values in geometric progression 42,63 , and $94.5 \mathrm{kN}$ that are higher than those used in the experiments. For the workpiece diameter $\left(d_{0}\right)$, we selected two values that are symmetrically arranged around the one used in the experiments (determined by the law of volume constancy $^{1}$ ): 18.75 and $18.85 \mathrm{~mm}$ for the metric profile, respectively, 18.82 and $18.92 \mathrm{~mm}$ for the trapezoidal profile. The different numerical simulations are detailed in Table 5.

\section{Results and discussions}

The simulations results that were analyzed in this study are:

- the profile forming time $\left(t_{\mathrm{d}}\right)$, the maximum radial force $\left(F_{\mathrm{r} \max }\right)$, and the distribution of equivalent deformations $\bar{\varepsilon}(\mathrm{PEEQ})$ in the axial section of the profiles, for the simulations in which the maximum

\begin{tabular}{|c|c|c|c|c|c|c|c|c|c|c|c|c|}
\hline \multirow[t]{2}{*}{ Profile } & \multicolumn{2}{|c|}{$d_{\mathrm{e}}(\mathrm{mm})$} & \multicolumn{2}{|c|}{$d_{\mathrm{i}}(\mathrm{mm})$} & \multicolumn{2}{|c|}{$h_{\mathrm{d}}(\mathrm{mm})$} & \multicolumn{2}{|c|}{$H(\mathrm{~mm})$} & \multicolumn{2}{|c|}{$F_{\mathrm{r} \max }(\mathrm{kN})$} & \multicolumn{2}{|c|}{$\mathrm{HV}(\mathrm{MPa})$} \\
\hline & exp. & sim. & exp. & sim. & exp. & sim. & exp. & sim. & exp. & sim. & exp. & sim. \\
\hline $\begin{array}{l}\text { M } 20 \\
\operatorname{Tr} 20\end{array}$ & $\begin{array}{l}19.858 \\
20.232\end{array}$ & $\begin{array}{l}19.934 \\
19.838\end{array}$ & $\begin{array}{l}17.8 \mid 8 \\
|7.48|\end{array}$ & $\begin{array}{l}17.831 \\
17.495\end{array}$ & $\begin{array}{l}0.491 \\
0.694\end{array}$ & $\begin{array}{l}0.484 \\
0.682\end{array}$ & $\begin{array}{l}1.02 \\
1.375\end{array}$ & $\begin{array}{l}1.051 \\
1.171\end{array}$ & $\begin{array}{l}22.94 \\
30.14\end{array}$ & $\begin{array}{l}22.13 \\
27.91\end{array}$ & $\begin{array}{l}>2370 \\
>2470\end{array}$ & $\begin{array}{l}>2440 \\
>2440\end{array}$ \\
\hline
\end{tabular}

Table 4. Synthesis of the comparisons: simulated results versus experimental results. 
Table 5. Variation of the process parameters in the numerical simulations.

\begin{tabular}{llllll}
\hline Simulated case nb. & \multicolumn{2}{l}{ Profile M20 } & & \multicolumn{2}{l}{ Profile Tr20 } \\
\cline { 2 - 3 } \cline { 5 - 6 } \cline { 5 - 6 } & $F_{\mathrm{m}}(\mathrm{kN})$ & $d_{0}(\mathrm{~mm})$ & & $F_{\mathrm{m}}(\mathrm{kN})$ & $d_{0}(\mathrm{~mm})$ \\
\hline 1 & 28 & 18.75 & & 28 & 18.82 \\
2 & & 18.85 & & 18.92 \\
$3^{*}$ & & 18.80 & & 18.87 \\
5 & 42 & & & 42 & \\
6 & 63 & & & 63 & \\
\hline
\end{tabular}

*Experimental case.

set force $\left(F_{\mathrm{m}}\right)$ was varied (simulated cases 3-6, see Table 5);

- the profile dimensions (internal diameter $d_{\mathrm{i}}$ and outer diameter $\left.d_{\mathrm{e}}\right)$, the depth of deformation $\left(h_{\mathrm{d}}\right)$, and the equivalent strain distribution $\bar{\varepsilon}(\mathrm{PEEQ})$ in the axial section of the profiles, for the simulations in which the workpiece diameter $\left(d_{0}\right)$ was varied (simulated cases 1-3, see Table 5).

\section{Influence of the maximum set force}

The profile forming time $\left(t_{d}\right)$ was estimated by imposing in equation (1) the condition of forming a depth as close as possible to the theoretical maximum $\left(h_{\max }\right)$. For a forming degree of the profile of $99 \%$ $\left(h=0.99 \cdot h_{\text {max }}\right)$, this condition leads to the following relation:

$$
\mathrm{t}_{\mathrm{d}}=\left(-\frac{\ln 0.01}{\beta}\right)^{\frac{1}{\alpha}}
$$

The dependence of the profile forming time $\left(t_{\mathrm{d}}\right)$ on the maximum set force $\left(F_{\mathrm{m}}\right)$ is obtained by inputting in the relation (8) the values of the coefficients $\alpha$ and $A$ that are expressed by the relations (2) and (3):

$$
\mathrm{t}_{\mathrm{d}}=\left(-\frac{\ln 0.01}{C \cdot v^{X_{\beta}} F_{m}{ }^{Y_{\beta}}}\right)^{\frac{1}{C_{\alpha \cdot} \cdot \gamma^{X_{\alpha}} F_{m}^{Y_{\alpha}}}}=\left(\frac{C_{1}}{F_{m} Y_{\beta}}\right)^{\frac{C_{2}}{F_{m} Y_{\alpha}}}
$$

where $C_{1}$ and $C_{2}$ are invariable in relation to the maximum set force $F_{\mathrm{m}}$ :

$$
\mathrm{C}_{1}=-\frac{\ln 0.01}{C \cdot v^{X_{\beta}}} \text { and } \mathrm{C}_{2}=\frac{1}{C_{\alpha} \cdot v^{X_{\alpha}}}
$$

Considering the values expressed in Table 2 for the six coefficients $C_{\alpha}, X_{\alpha}, Y_{\alpha}, C_{\beta}, X_{\beta}, Y_{\beta}$ it results that the dependence of $t_{\mathrm{d}}$ on $F_{\mathrm{m}}$ follows a hyperbolic shape, which is represented graphically in Figure 6.

The analysis of these dependencies allows drawing the following conclusions:

- For a given value of the maximum set force $\left(F_{m}\right)$ the trapezoidal profile forming time is lower than the metric one. Because deformation during thread

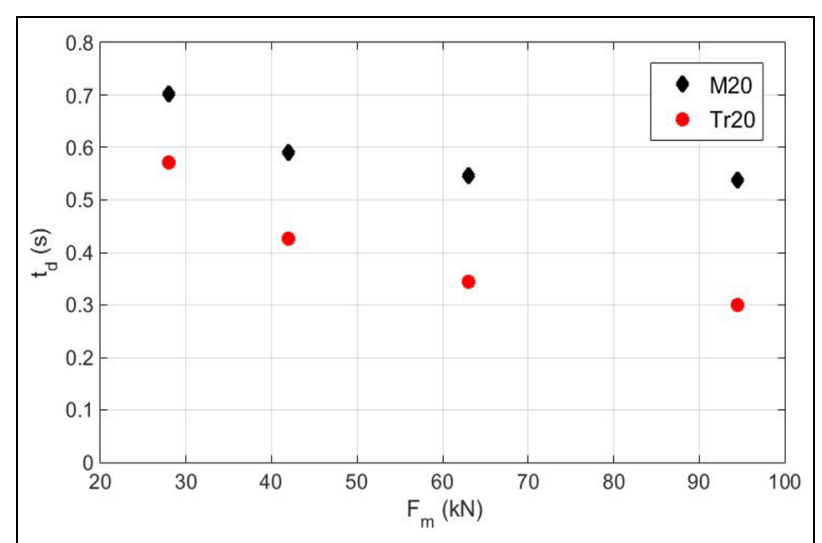

Figure 6. The dependence between the profile forming time, $t_{d}$, and the maximum set force, $F_{m}$.

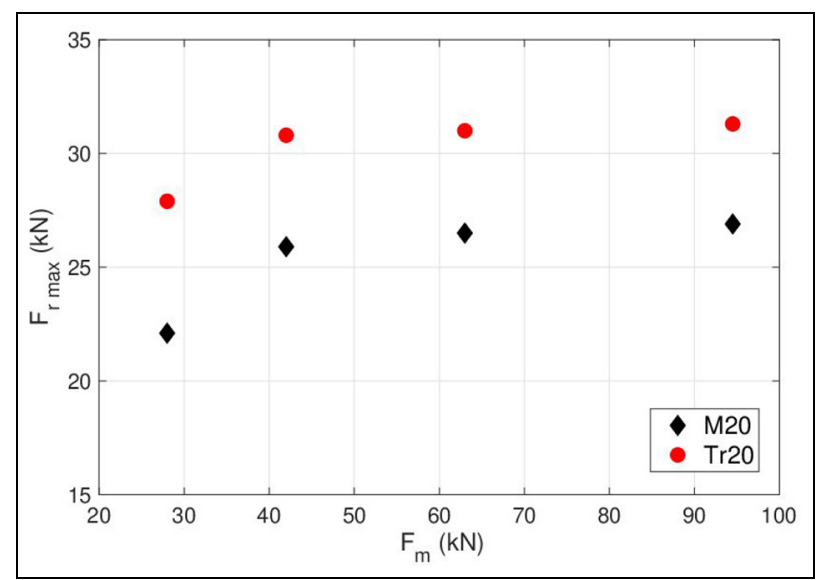

Figure 7. The dependency between the maximum radial force $F_{r \text { max }}$ and the maximum set force, $F_{m}$.

rolling closely resembles the indentation of a semiinfinite body, ${ }^{13,36}$ the favorable geometry of the trapezoidal profile (lower flank angle) explains this evolution, leading to the rapid penetration of the roller-tools in the workpiece.

- There is a slight flattening trend of the two curves, which is found at the values of the maximum set force $F_{m}$ greater than $60 \mathrm{kN}$ for the metric profile, respectively, $90 \mathrm{kN}$ for the trapezoidal profile. This finding is related to the hyperbolic shape of the dependence between $t_{\mathrm{d}}$ and $F_{\mathrm{m}}$ (see equation (10)). These evolutions of the profile forming time are due to the behavior of the material, namely its hardening: in the plastic deformation domain, according to the constitutive equation of the material, ${ }^{37}$ the increase in tension becomes smaller and smaller as the deformation increases, thus slowing down the intensity of the deformation process and, consequently, the increase of the profile forming duration.

The dependency of the maximum radial force $\left(\boldsymbol{F}_{\boldsymbol{r} \text { max }}\right)$ on the maximum set force $F_{m}$ is shown graphically in Figure 7. 


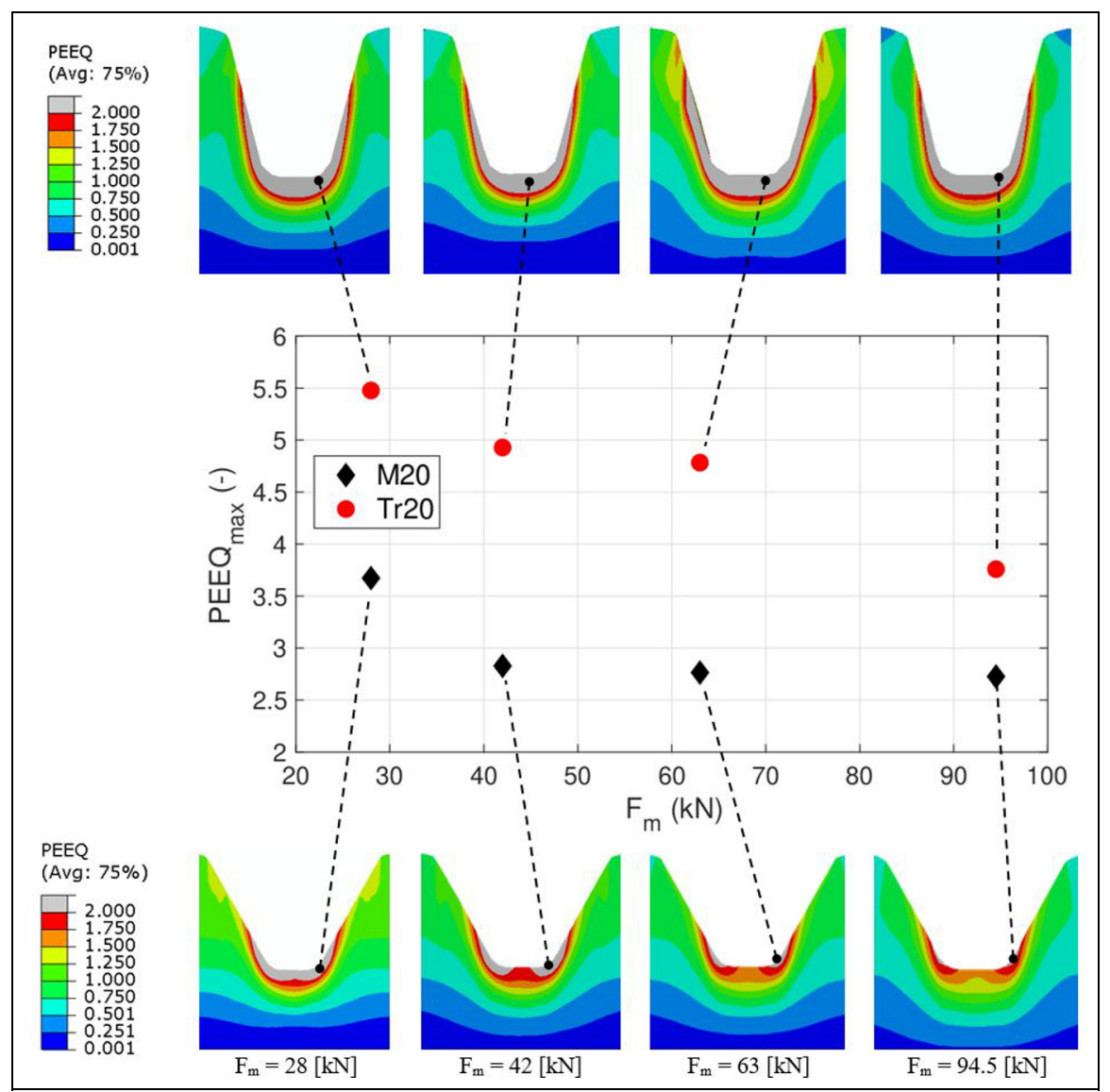

Figure 8. Distribution of the equivalent plastic strains (PEEQ) with respect to the maximum set force $F_{m}$.

It is found that for the same value of the maximum set force $\left(F_{m}\right)$, the maximum radial force $\left(F_{r}\right.$ max $)$ is higher for the trapezoidal profile than for the metric one. This is because the flat base of the trapezoidal indenter (roller-tools) leads to deeper penetration and hardening of the workpiece. ${ }^{14}$

There is a trend of flattening for the two curves which appears when the maximum set force $\left(F_{\mathrm{m}}\right)$ exceeds $42 \mathrm{kN}$. The levels of these flattenings are $2 \mathrm{kN}$ for the metric profile and $32 \mathrm{kN}$ for the trapezoidal profile. This flattening is because the maximal radial force depends on the penetration depth of the tool into the workpiece $(h)$ and this maximum penetration depth is limited to a required value $\left(h_{\max }\right)$ which depends on $d_{0}$ and $d_{i}$ (see equation (6)).

Figure 8 shows the distribution of the equivalent plastic strains $\overline{\boldsymbol{\varepsilon}}(\boldsymbol{P E E Q})$ in the axial section of the profiles and the dependence between the maximum values PEEQ and the maximum set force value. Values and distribution of the PEEQ in the formed profile give information about the degree of deformation of the profile and its hardness level, and its analysis allows us to draw the following conclusions:

- The largest strains always appear at the bottom of the profile (the maximum value being in the root of the flank) and are propagated radially toward the interior of the material. Although these strains within the tooth are lower, the tooth is hardened $(\bar{\varepsilon} \geqslant 0.5 \Rightarrow \mathrm{HV} \geqslant 2130 \mathrm{MPa})$.

- For the metric profile, the material hardening is significantly influenced by the maximum set force $\left(F_{m}\right)$. For example, the most hardened area $(\bar{\varepsilon} \geqslant 2 \Rightarrow \mathrm{HV} \geqslant 2440 \mathrm{MPa}$ ), (i) differs in terms of size and position: it is greater and more present in the bottom of the profile and at the root of the flank, when processing with a lower maximum set force, and (ii) it becomes smaller and smaller and localizes at the root of the flanks with the increase of the maximum set force.

- For the trapezoidal profile, the material hardening is less dependent on the maximum set force, the area strongly hardened $(\bar{\varepsilon} \geqslant 2)$ varying less.

- The maximum material hardening is obtained in the cold rolling process with lower maximum set forces, meaning that the penetration of the roller-tools is performed at lower feeds. The material hardening is greater in the cold rolling process for the trapezoidal profile than the metric one and this can be explained by the greater forming depth of the profile. ${ }^{13,14}$

\section{Influence of the workpiece diameter}

The profile's dimensions obtained by simulations when the workpiece diameter was varied are presented in Figure 9. The increase in the workpiece diameter $\left(d_{0}\right)$ 


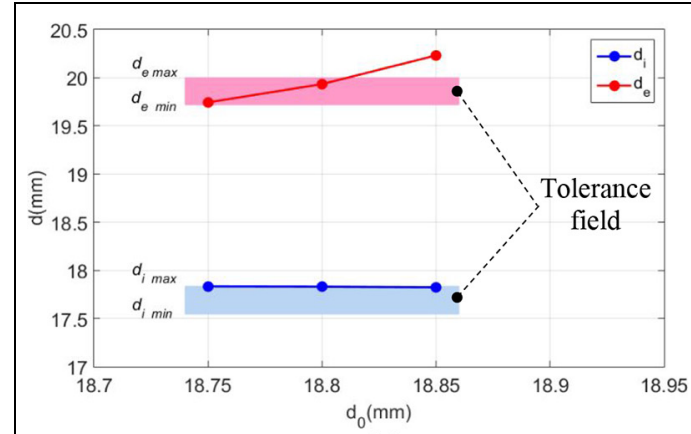

(a)

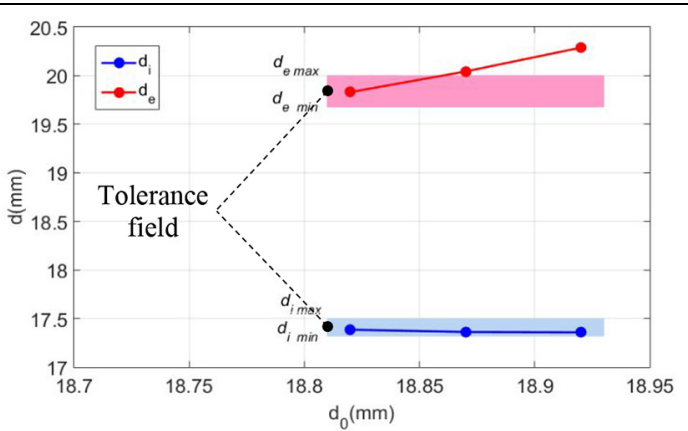

(b)

Figure 9. Dependence of the profiles diameters obtained by radial cold rolling with respect to the workpiece diameter: (a) metric profile and (b) trapezoidal profile.

leads as expected, considering the volume conservation law and the constant position of buffers, to the increase in both the deformation depth $\left(h_{d}\right)$ and the outer diameter $\left(d_{e}\right)$.

Regarding the tolerance margin of both the inner and the outer diameters of the profiles, it can be seen that:

- For the metric profile, the resulted dimensions are adequate if using a workpiece with a smaller or equal diameter to the one determined by the law of volume constancy $\left(d_{0} \leqslant 18.80 \mathrm{~mm}\right)$;

- For the trapezoidal profile, the obtained dimensions are appropriate if using a workpiece with a diameter smaller than the one determined by the law of volume constancy $\left(d_{0}<18.87 \mathrm{~mm}\right)$.

The distribution of the equivalent plastic strains $\overline{\boldsymbol{\varepsilon}}(\boldsymbol{P E E Q})$ in the axial section of the profiles and the dependence of the maximum values PEEQ with respect to the workpiece diameter are shown in Figure 10. A slight increase can be noticed in the maximum level of the equivalent plastic strains as well as in the depth of the zone strongly deformed when increasing the workpiece diameter. This fact is due to the increase in the deformation depth $\left(h_{d}\right)$ (see equation (6)), which leads to an increase in the degree of deformation of the profile. $^{38}$

\section{Summary and conclusions}

The research presented in the paper consisted of running several numerical simulations of the cold-rolling process with two roller-tools, of radial grooves with metric and trapezoidal profile, using a numerical model previously validated. The penetration curve of the roller-tools in the material was introduced in the simulation as an analytical function and was determined based on experimental researches. The dependence of the curve penetration coefficients on the rolling conditions (rolling speed, $v$, and maximum set force, $F_{\mathrm{m}}$ ) was established by a multivariable analysis using the design of the experiment technique.
The varied parameters in the simulations were the maximum set force $\left(F_{\mathrm{m}}\right)$ and the diameter of the workpiece $\left(d_{0}\right)$. The analyzed results were the profile forming time $\left(t_{\mathrm{d}}\right)$, the maximum radial force $\left(F_{\mathrm{m}}\right)$, the distribution of the equivalent plastic strains in the axial section of the profiles (PEEQ), and the profile dimensions $\left(d_{\mathrm{e}}\right.$ and $\left.d_{\mathrm{i}}\right)$.

The main conclusions drawn from this work can be summarized as follows:

- rolling with higher maximum set forces leads to (i) decreasing the profile forming time $\left(t_{\mathrm{d}}\right)$ up to a limit level, (ii) increasing the radial maximum force $\left(F_{\mathrm{r}}\right.$ $\max$ ) up to a limit level, and (iii) decreasing the area strongly hardened and the maximum values of equivalent plastic strains (PEEQ) in the axial section of the rolling profiles.

- the use of workpieces with a smaller diameter than the one determined by the law of volume constancy leads to profiles with conforming dimensions (within the specified tolerance field), while the inner diameter of the profile is directly influenced by the adjusting dimension and the stiffness of the technological system.

To define the optimal process conditions, the following criteria are considered:

- Productivity, which can be appreciated with the profile forming time $\left(t_{\mathrm{d}}\right)$;

- Material hardening, which can be appreciated based on the distribution and the level of the equivalent plastic strains (PEEQ);

- Profile dimensions, described by the inside diameter $d_{\mathrm{i}}$ and the outer diameter $d_{\mathrm{e}}$.

Based on the results analyzed in section 4 and on the optimality criteria defined above, we can establish the optimum process conditions:

- to obtain a good compromise between high productivity (lower profile forming time) and a higher and more uniform material hardening (PEEQ maximum), the value of the maximum set force $\left(F_{m}\right)$ should not be too high. In this study, the following 


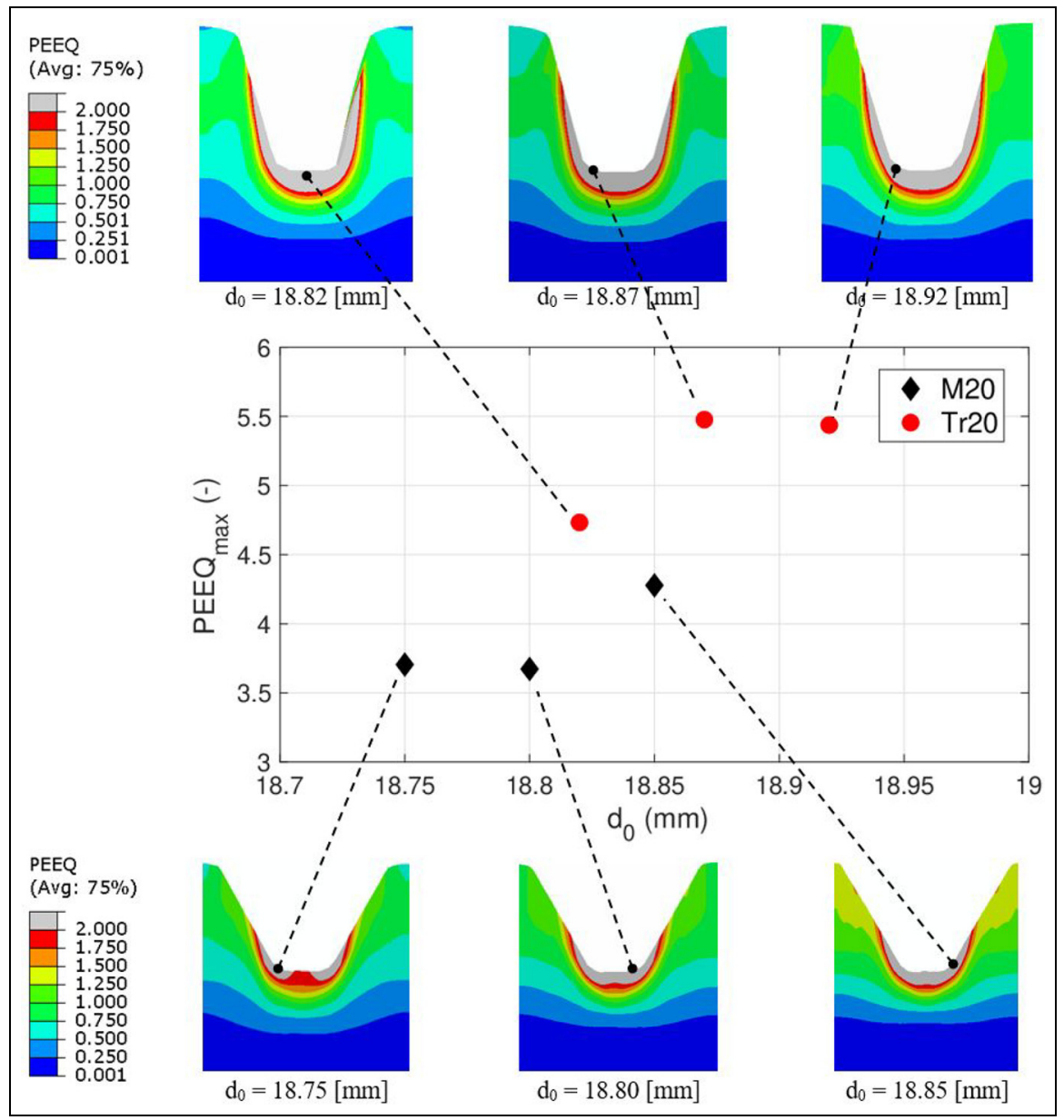

Figure 10. Distribution of the equivalent plastic strains (PEEQ) with respect to the workpiece diameter, $d_{0}$.

values are considered as suitable: $F_{m}$ between 40 and $50 \mathrm{kN}$ for the rolling of the metric profile, and $F_{m}$ between 50 and $60 \mathrm{kN}$ for the rolling of the trapezoidal profile, respectively.

- to obtain dimensions of the profile within the specified tolerance field, the diameter $d_{0}$ of the workpiece must be between 18.75 and $18.80 \mathrm{~mm}$ for the rolling of the metric profile, and between 18.79 and $18.84 \mathrm{~mm}$ for the rolling of the trapezoidal profile, respectively.

Further research can be done by considering another parameter of the process, for example, the radius of the tip of the tool, or by extending the investigations to other profiles or materials used in this field.

\section{Declaration of conflicting interests}

The author(s) declared no potential conflicts of interest with respect to the research, authorship, and/or publication of this article.

\section{Funding}

The author(s) received no financial support for the research, authorship, and/or publication of this article.

\section{ORCID iD}

Eduard Laurentiu Nitu (iD) https://orcid.org/0000-00034571-3488

\section{References}

1. Neagu C, Vlase A and Marinescu N. Cold volumetric pressing of parts with thread and teeth (in romanian). Bucureşti: Editura Tehnică, 1994.

2. Ernst Grob. Cold forming solid materials, http:// www.ernst-grob.com/en/processes/cold-forming-solidmaterials/cold-forming-rolling-solid-materials.html (accessed 20 June 2019).

3. Escofier. Roulage de Filetages - Moletages, http://www. escofier.com/produits/roulage-de-filetages-modelages? lang $=$ en (accessed 20 June 2019).

4. LMT Tools. Thread rolling heads, http://www.lmt-tools. com/products/tags/thread-rolling-heads/ (accessed20 June 2019).

5. Reed Machinery. Thread form rolling applications, http://www.reed-machinery.com/thread-and-form-rolling-applications/ (accessed 20 June 2019).

6. Lindsay G. Rolled vs cut thread bolts. USA: Portland Bolt, http://www.portlandbolt.com/technical/faqs/rolledvs-cut-threads-bolts/ (2017, accessed 20 June 2019).

7. Iacomi D, Iordache $\mathrm{M}$ and Nitu E. Comparative study concerning the generation of some circular grooves by 
cold rolling with wedge tools and cutting. Adv Mat Res 2014; 1036: 298-303.

8. Nitu E, Iordache M and Iacomi D. Comparative study concerning the generation of some circular grooves by radial cold rolling with roller tools and cutting. Adv Mat Res 2014; 1036: 246-251.

9. Peng B, Luo Y, Luo Y, et al. Geometry optimization of the rolling tool for gear roll-forming process. Proc IMechE, Part B: J Engineering Manufacture. Epub ahead of print 28 August 2020. DOI: 10.1177/ 0954405420951101.

10. Rowe GW, Sturges CEN, Hartley P, et al. Finite-element plasticity and metalforming analysis. Cambridge: Cambridge University Press, 1991.

11. Martin JA. Fundamental finite element evaluation of a three dimensional rolled thread form: Modelling and experimental results, https://www.osti.gov/servlets/purl/ 304177 (1998, accessed 19 June 2019).

12. Martin JA. A finite element evaluation of residual stress in a thread form generated by a cold-rolling process. Fatigue Fract Resid Stress 1999; 393: 239-253.

13. Domblesky JP and Feng F. Two-dimensional and threedimensional finite element models of external thread rolling. Proc IMechE, Part B: J Engineering Manufacture 2002; 216(4): 507-517.

14. Domblesky JP and Feng F. A parametric study of process parameters in external thread rolling. J Mat Process Technol 2002; 121: 341-349.

15. Kamouneh A, Ni J, Stephenson D, et al. Investigation of work hardening of flat-rolled helical-involute gears through grain-flow analysis, FE-modeling and strain signature. Int $J$ Mach Tools Manuf 2007; 47: 1285-1291.

16. Kamouneh A, Ni J, Stephenson D, et al. Diagnosis of involumetric issues in flat rolling of external helical gears through the use of finite-elements models. Int $J$ Mach Tools Manuf 2007; 47: 1257-1262.

17. Song JH, Lee $\mathbf{J}$, Lee HJ, et al. Analysis and experiments on the thread rolling process for micro-sized screws, Part I: process parameter analysis by finite-element simulation. Trans Mat Process 2011; 20(8): 580-587.

18. Kowalik M and Trzepieciński T. Numerical and experimental estimation of forces during longitudinal rolling process of shaft formation. Arab J Sci Eng 2014; 39: $1251-1260$

19. Kukiełka K, Kukiełka L, Bohdal $€$, et al. 3D numerical analysis the state of elastic/viscoplastic strain in the external round thread rolled on cold. Appl Mech Mat 2014; 474: 436-441.

20. Cui MC, Zhao SD, Zhang DW, et al. Deformation mechanism and performance improvement of spline shaft with $42 \mathrm{CrMo}$ steel by axial-infeed incremental rolling process. Int J Adv Manuf Technol 2017; 88: 26212630.

21. Ma Z, Luo Y and Wang Y. On the pitch error in the initial stage of gear roll-forming with axial-infeed. $J$ Mater Process Technol 2018; 252: 659-672.
22. Ma Z, Luo Y, Wang Y, et al. Geometric design of the rolling tool for gear roll-forming process with axialinfeed. J Mater Process Technol 2018; 258: 67-79.

23. Kramer $\mathbf{P}$ and Groche P. Defect detection in thread rolling processes - experimental study and numerical investigation of driving parameters. Int $J$ Mach Tools Manuf 2018; 129: 27-36.

24. Yuan W, Zhang Q, Jia L, et al. The influence of roller motion on profile and hardness of T2 worm. IOP Conf Ser Mater Sci Eng 2018; 392: 148-156.

25. Zhang S, Fan S, Wang Q, et al. Deformation characteristics of self-infeed rolling processfor thread shaft. Int $J$ Adv Manuf Technol 2019; 103: 2941-2951.

26. Zhang S, Fan S, Zhang P, et al. The formation mechanism of protrusion of long thread by axial self-infeed rolling process. Proc IMechE, Part B: $J$ Engineering Manufacture 2020; 234(10): 1302-1310.

27. Ungureanu I, Nitu E, Iordache M, et al. Roller tool device and system for machining profiled circular grooves on cylindrical pieces by cold plastic deformation. Patent RO126192, Romania, 2014.

28. Iordache M, Iacomi D and Nitu E. Device and experimental stand to process profiles by radial cold rolling with roller tools. Sci Bull Series B Univ Pitesti 2013; 23(B): 74-80.

29. Nitu E, Ungureanu I, Ferron G, et al. Analytical modelling of the process of cold rolling by in-feed method. In: Academic Journal of Manufacturing Engineering. Proceedings of the 5 th international conference on manufacturing science and education (ed Duşe DM), 2011, pp.207214. Sibiu: "Lucian Blaga" University of Sibiu.

30. Goupy JL. Methods for experimental design: principles and applications for physicists and chemists. Paris: Elsevier, 1993.

31. Goupy JL. Les plans d'experiences: Optimissation du choix des essais et de l'interpretation des resultats.5th ed. Paris: Dunod, 2013.

32. Nitu E, Iordache M, Marincei L, et al. FE-modeling of cold rolling by in-feed method of circular grooves. Stroj Vest J Mech Eng 2011; 57(9): 667-673.

33. McConnell $\mathrm{C}$ and Lenard JG. Friction in cold rolling of a low carbon steel with lubricants. J Mat Process Technol 2000; 99: 86-93.

34. Fares Y. Fatigue design of bolted assembly using multiaxial fatigue criteria. PhD Thesis, INSA Toulouse, Toulouse, 2006.

35. Tabor D. The hardness and strength of materials. J Inst Metals 1951; 79: 1-18.

36. Kim W, Kawai K and Koyama H. Metal flow in wedge indentation of $\mathrm{V}$ - and $\mathrm{W}$-shaped tools. J Mater Process Technol 2007; 189: 392-400.

37. Iordache M, Niţu E and Iacomi D. Determination of constitutive equation at the deformation of materials using the compression test. Adv Mat Res 2014; 837: 110 115 .

38. Herold K. Berechnung des Umformgrades beim Gewindewalzen. Umformtechnik 1983; 17(6): 237-243. 


\section{Appendix}

\section{List of notations}

\begin{tabular}{|c|c|}
\hline Abbreviations & Significance \\
\hline$a_{\mathrm{e} \max }$ & maximum deviation of the outer diameter \\
\hline$a_{\mathrm{e} \min }$ & minimum deviation of the outer diameter \\
\hline$a_{\mathrm{i} \max }$ & $\begin{array}{l}\text { maximum deviation of the internal } \\
\text { diameter }\end{array}$ \\
\hline$a_{\mathrm{i} \min }$ & $\begin{array}{l}\text { minimum deviation of the internal } \\
\text { diameter }\end{array}$ \\
\hline$d_{e}$ & outer diameter \\
\hline$d_{i}$ & internal diameter \\
\hline$d_{0}$ & workpiece diameter \\
\hline$d_{w r}$ & workpiece gap \\
\hline$f$ & yield function \\
\hline$h$ & penetration depth of the roller-tools \\
\hline$h_{\mathrm{d}}$ & depth of deformation \\
\hline$h_{\max }$ & $\begin{array}{l}\text { maximum penetration depth of the roller- } \\
\text { tools }\end{array}$ \\
\hline$n$ & $\begin{array}{l}\text { coefficient of the Hollomon and Voce's } \\
\text { law }\end{array}$ \\
\hline$n_{r}$ & Roller speed \\
\hline$n_{w}$ & workpiece speed \\
\hline$p$ & thread pitch \\
\hline$P_{\mathrm{h}}$ & pressure in the hydraulic engine \\
\hline$s_{i j}$ & deviatoric stress components \\
\hline$s_{\mathrm{r}}$ & radial feed of the roller-tools \\
\hline$t$ & process time \\
\hline$t_{\mathrm{d}}$ & profile forming time \\
\hline$v$ & rolling speed \\
\hline$A$ & $\begin{array}{l}\text { coefficient of the Hollomon and Voce's } \\
\text { law }\end{array}$ \\
\hline B & $\begin{array}{l}\text { coefficient of the Hollomon and Voce's } \\
\text { law }\end{array}$ \\
\hline
\end{tabular}

Appendix. Continued

\begin{tabular}{|c|c|}
\hline Abbreviations & Significance \\
\hline$C_{\alpha}$ & coefficient of the $\alpha$ function \\
\hline$C_{\beta}$ & coefficient of the $\beta$ function \\
\hline$E^{\beta}$ & Young's modulus \\
\hline$F_{\mathrm{m}}$ & maximum set force \\
\hline$F_{\mathrm{r}}$ & radial force \\
\hline $\begin{array}{l}F_{r} \max \\
H\end{array}$ & $\begin{array}{l}\text { maximum radial force } \\
\text { profile height }\end{array}$ \\
\hline HV & Vickers microhardness \\
\hline$K$ & $\begin{array}{l}\text { coefficient of the Hollomon and Voce's } \\
\text { law }\end{array}$ \\
\hline PEEQ & equivalent strains \\
\hline RS & support ruler \\
\hline RT & roller-tools \\
\hline$R^{2}$ & $\begin{array}{l}\text { coefficient of determination (regression } \\
\text { analysis) }\end{array}$ \\
\hline$S$ & $\begin{array}{l}\text { coefficient of the Hollomon and Voce's } \\
\text { law }\end{array}$ \\
\hline WP & workpiece \\
\hline$X_{\alpha}$ & coefficient of the $\alpha$ function \\
\hline$X_{\beta}$ & coefficient of the $\beta$ function \\
\hline$Y_{\alpha}^{\rho}$ & coefficient of the $\alpha$ function \\
\hline$Y_{\beta}$ & coefficient of the $\beta$ function \\
\hline$\alpha$ & $\begin{array}{l}\text { coefficient of the curves of the } \\
\text { penetration of the roller-tools in the } \\
\text { workpiece, associated with the process } \\
\text { time variable }\end{array}$ \\
\hline$\beta$ & $\begin{array}{l}\text { coefficient of the curves of the } \\
\text { penetration of the roller-tools in the } \\
\text { workpiece, associated with the } \\
\text { exponential function }\end{array}$ \\
\hline$\varepsilon$ & effective strain \\
\hline$\nu$ & Poisson's ratio \\
\hline$\theta$ & flank angle \\
\hline $\bar{\sigma}$ & current yield stress \\
\hline
\end{tabular}

